\title{
Is Technology Value-Neutral?
}

\author{
Boaz Miller \\ Community Information Systems, Zefat Academic College \\ boaz.m@zefat.ac.il
}

Forthcoming in Science, Technology, and Human Values.

\begin{abstract}
According to the Value Neutrality Thesis, technology is morally and politically neutral, neither good nor bad. A knife may be put to bad use to murder an innocent person, or to good use to peel an apple for a starving person, but the knife itself is a mere instrument, not a proper subject for moral or political evaluation. While contemporary philosophers of technology widely reject the Value Neutrality Thesis, it remains unclear whether claims about values in technology are just a figure of speech, or non-trivial empirical claims with genuine factual content and real-world implications. This paper provides the missing argument. I argue that by virtue of their material properties, technological artifacts are part of the normative order, rather than external to it. I illustrate how values can be empirically identified in technology. The reason why value-talk is not trivial or metaphorical is that due to the endurance and longevity of technological artifacts, values embedded in them have long-term implications that surpass their designers and builders. I further argue that taking sides in this debate has real-world implications in the form of moral constraints on the development of technology.
\end{abstract}

Keywords Technology, Values, Value-Neutrality, Artifacts

\section{Introduction}

According to the Value-Neutrality Thesis (VNT), technology is morally and politically neutral, neither good nor bad; only its uses have moral or other value, not the technology itself. A knife may be used to murder an innocent person, or peel an orange for a starving person, but the knife itself is a mere instrument, not subjectable to moral evaluation.

While contemporary academic philosophers and theorists of technology from different schools widely reject VNT, ${ }^{1}$ it remains unclear whether claims about values in technology are more than just a figure of speech; namely, whether they are non-trivial empirical claims with genuine factual content and real-world implications. This challenge has been most thoroughly developed by Joseph Pitt, who, primarily in his paper “Guns don't kill, people kill,” gives an explicit full-fledged argument for VNT (Pitt 2014; Pitt 2000: 72-86). The absence of a satisfactory 
response to Pitt's challenge may partly explain why VNT remains a common platitude in the general public and among technology developers.

In this paper, I argue-against Pitt-that by virtue of their material properties, technological artifacts are part of the normative moral and political order, rather than external to it. I illustrate how values can be empirically identified in technology. The reason why valuetalk is not trivial or metaphorical is that due to the endurance and longevity of technological artifacts, values embedded in them have long-term implications that surpass their designers and builders. Furthermore, accepting or denying VNT has real-world implications in the form of moral constraints on the development of technology.

Section 2 critically reviews Pitt's argument for VNT and the main arguments against VNT. Section 3 argues that values need not be empirically identified to be embedded in material technological artifacts. Section 3 argues notwithstanding that values can be empirically identified in material technological artifacts, and introduces a sufficient condition for values to be embedded in an artifact. Section 5 argues that the claim that technology embodies values is not trivial because values materially endure in technology. Section 6 argues that denying VNT does not relinquish technologists from their moral responsibilities, and Section 7 argues that the philosophical debate about VNT has real-world moral practical implications.

\section{The arguments for and against VNT}

Pitt (2014: 90) formulates VNT as follows:

(VNT) Technological artifacts do not have, have embedded in them, or contain values.

Pitt's argument can be reconstructed as follows:

(VNT1) For technological artifacts to embody, embed, or contain values in a non-trivial sense, these values must be empirically identifiable from the technological artifacts in which they are embedded. 
(VNT2) Values are not empirically identifiable from technological artifacts.

(VNT3) Therefore, either technological artifacts do not embody, embed, or contain values at all, or they do so only in a trivial sense.

Two preliminaries are in order. First, defining "technology" is hard (Agassi 1985: 21-26) and exceeds the scope of this paper. It suffices that the concept of technology in question is narrow, referring to technological artifacts; namely, artificial material objects designed to perform functions, rather than comprehensive systems, such as state bureaucracy or a city.

Second, let us review the case against VNT to clarify its weakness. A typical argument against VNT if twofold: (1) conceptual illumination and refinement of VNT; (2) empirical examples that clearly contradict VNT in its refined form; namely, empirical cases of technology that is clearly value-laden.

A good example of this strategy is van de Poel and Kroes (2014), who clarify that if values are embedded in an artifact, this must be due to its own physical properties; while a rare stamp may be valuable, it does not embody value due to its rarity, because being rare is not a physical property. Drawing on G.E. Moore's taxonomy of values, they distinguish four types of values that objects may putatively have: intrinsic-final, extrinsic-final, intrinsic-instrumental, and extrinsicinstrumental. Being extrinsic means that the content of these values is relative to some human normative evaluation framework. Being final means that the artifacts are not merely instruments for achieving other values that reside elsewhere. They argue that if technology possesses values at all, they must be extrinsic-final. ${ }^{2}$

The distinction between final and extrinsic values helps clarify what the value-neutrality debate is about. Being extrinsic means that values in an artifact are relative to two contexts: an evaluation system, which ranks some possible states of affairs as more desirable than others, and a context of use, in which normative judgments can be passed according to this evaluation system. A gun floating free in outer space lacks such contexts, and is therefore value neutral. If 
the gun is found by aliens whom it cannot harm, then within this new context of use, it does not embody the values it arguably embodies for humans. But that values are relative to a context does not rest the debate about VNT, because we may still ask where the values reside within a context, in the artifact, as opponents of VNT would argue, or only in the context, as its proponents would argue. VNT proponents might argue that values come only from the ways an artifact is used in a context, while VNT opponents would insist that within a context, an artifact may embody values and partly shape the context itself regardless of whether and how it is used.

After characterizing putative values in technology as extrinsic-final, van de Poel and Kroes point out examples of technologies that, so they argue, manifestly possess values, because they have a clear, undeniable value-laden function. One such example is sea dikes, which clearly possess the value of safety:

Dikes are thus designed for safety [...] Whereas in the case of the knife, the function of the artifact and the final values that can be achieved by realizing the function are clearly separated, this is not the case in the sea dike example. The instrumental function of sea dikes (protection from flooding) can hardly be distinguished from the final value for which they are designed (safety with regard to flooding) [...] If such expressions make sense, then it follows immediately that technical artifacts, as objects with a function, may embody extrinsic final values, since functions are extrinsic features of technical artifacts (van de Poel and Kroes 2014: 114).

A famous example of manifestly value-laden technology is the low-clearance bridges over the Long Island parkways, which allegedly embody racist values. ${ }^{3}$ Winner (1980) argues that city-planner Robert Moses (1888-1981) intentionally designed extraordinarily low overpasses over the Long Island parkways to prevent buses from passing under them, thus preventing AfroAmerican public-transit users from accessing the Long Islands beaches. Winner argues that the physical features that lade an artifact with values may be part of the technological type, and then the technology itself is value laden, or may only be part of the token, such that specific artifacts are value laden, but not the technology as such. Winner's claims have become canonical, but they 
have also been historically disputed (Joerges 1999; Woolgar and Cooper 1999). For the sake of the argument, and without taking a stand in the historical dispute, I will treat them as true.

Another line of argument against VNT comes from Verbeek's (2011) mediation theory, which builds on Ihde's (2009) postphenomenological philosophy of technology. According to mediation theory, rather than merely extending or enhancing human capacities, technology mediates between humans and the world, actively shaping both sides. A careful phenomenological analysis of this mediation may reveal how a technology is not a neutral instrument. For example, arguing against the slogan "guns don't kill, people kill," which Pitt endorses, Verbeek $(2008,98)$ writes:

A gun is not a mere instrument, a medium for the free will of human beings; it helps to define situations and agents by offering specific possibilities for action. A gun constitutes the person holding the gun as a potential gunman and his or her adversary as a potential lethal victim. Without denying the importance of human responsibility in any way, this example illustrates that when a person is shot, agency should not be located exclusively in either the gun or the person shooting, but in the assembly of both. ${ }^{4}$

This line of argument, however, has its difficulties. Phenomenology analyzes subjective experience. A VNT proponent might object that to acquire general validity, a phenomenological analysis requires intersubjective agreement, which may be difficult to achieve. People have different experience with the same technology. I carried an M-16 rifle for about three years of mandatory military service in a non-combative role. I did not feel like a potential gunman, but like carrying a heavy broomstick. By contrast, Geoffrey Canada, who grew up in the crime-ridden urban streets of the South Bronx, affirms Verbeek's claims about the deep effect of carrying a gun as a teen on him:

Carrying the gun had been like becoming a superhero. Suddenly I'd had power, real power. It had been intoxicating [...] I knew that if I continued to carry the gun I would soon or later pull the trigger (Canada 1995, 103). 
Which experience is more valid? Are values embedded in technology only a matter of subjective experience or opinion? Are they embedded for some but not others? How can people without relevant experience, such as people whose perceptions about guns come from popular culture, correctly judge the validity of phenomenological claims about a technology?

These questions are not intended to dispute mediation theory or to reject postphenomenological analyses of technology. My point is that an argument from a postphenomenological analysis against VNT risks overstating its case, preaching to the choir, or overshooting its target. It may not persuade, or be applicable to those whose personal experience with the technology is different or absent. This paper is a friendly supplement to mediation theory and its methodological toolbox.

In conclusion, the case against VNT hinges on the persuasiveness of its supportive empirical examples, i.e., whether one can directly empirically "see" or indirectly empirically identify the values in them. Pitt's argument for VNT heavily leans on this point. I now proceed to critically evaluating it.

\section{Need values be empirically identifiable from technological artifacts to be embedded in}

\section{them?}

Start with premise VNT1. Why need values be empirically recognizable to be embedded in material artifacts? At first blush, Pitt conflates an ontological question, i.e., whether values are present, and an epistemological question, i.e., whether they are empirically identifiable. Pitt does not explicitly defend VNT1, but two lines of defense may be extracted from his paper. First, Pitt is a pragmatist. Pragmatists hold that a metaphysical distinction is meaningless unless drawing it has tangible influence on our lives (James 1907: Ch. 3). Pitt seemingly assumes that for the question of values in technology to have tangible influence, values must be empirically identifiable. 
Pitt's second implicit defense of VNT1 stems from his pragmatist conception of values. Pitt adopts a conceptions of values as motivators of human action:

(VM) a value is an endorsement of a preferred state of affairs by an individual or group of individuals that motivates our actions (2014: 91).

VM is pragmatist in that it conceptually connects values and action. Pitt seemingly assumes that to motivate a person's actions, values must be empirically recognizable to her.

A different conception of values as normative discriminators is also possible:

(VND) a value is anything that serves as a basis for discriminating between different states of affairs and ranking some of them higher than others with respect to how much they are desired or cared about or how the personal, social, natural, or cosmic order ought to be (Miller 2014A: 70).

VND is preferable to VM for two reasons. First, VM risks begging the question for VNT by making values impossible to be embedded in material objects by definition. Despite Pitt's claim to the contrary, it remains unclear whether action-motivating endorsements can be embedded in material objects. By contrast, VND is neutral on the metaphysics of values, and does not rule out their being materially embedded.

Second, the relation between values and motivations is not conceptually necessary. Adhering to a value is consistent with mere passive appreciation without any motivation to act. I may value the beauty of mathematics without having any motivation to practice mathematics or understand complex proofs. And it makes no sense to have "a motivation to act for mathematical beauty." I may value excellence in archery without having any motivation to practice or watch it. Against this, the pragmatist may deny that I value mathematical beauty or excellence in archery, because these values have no tangible influence on my conduct. But my point is exactly that VM stems from Pitt's extra commitment to pragmatism, rather than a genuine conceptual relation. 
It might be argued that regardless of the conceptual relations between values and motivations, VNT1 is still correct. This objection, however, fails. For example, a blind person may value excellence in archery in a way that impacts her life, e.g., she may collect memorabilia associated with great archers and admire them at bedtime, but she may be unable to recognize a good archer. Namely, an archer may embody the value of excellence while she cannot recognize it in the archer.

In fact, values in technology are so effective because they are often hardly empirically recognizable. In Winner's (1980) example, restricting Afro-Americans' access by political means would have probably raised opposition, whereas using bridge design circumvented political checks and controls. The low overpasses restricting Afro-Americans' access to public beaches go unnoticed. City benches divided into individual seats by high bars are effective in preventing the homeless from sleeping on them. While their sleep-prevention function may be more noticeable, it may still go mostly unnoticed because technology tends to become transparent or taken for granted (Rosenberg 2014: 376), like eyeglasses, which stop being noticed by their frequent wearers (Lehrer 1995: 162-165).

\section{4. "Show me the values!" Are values in technology empirically unidentifiable?}

So far I argued against VNT1, which states that for values to be embedded in technological artifacts, identifying them from the artifacts must be possible. I now move to argue against VNT2, which states that values are not empirically identifiable from technological artifacts. There is an apparent tension between denying VNT1 and denying VNT2 (if you deny that values need to be empirically identifiable to be embedded, why go on to argue that they are empirically identifiable nevertheless?) Let me explain my dialectics. I deny VNT1 inter alia by noting cases in which embedded values go unnoticed. Yet the fact that embedded values go unnoticed does not mean that they are empirically unidentifiable. Designers, historians and philosophers of technology, 
etc., may still identify them. It is consistent with my argument that we may have blind spots preventing us from identify all values in a technology.

The first reason, according to Pitt, that values are empirically unidentifiable from technological artifacts is that values are not directly readable off, or observable from design schematics or material artifacts. Pitt writes, referring to Winner's (1980) claim that Moses embedded the value of racism in the low overpasses over the Long Island Expressway:

Let us say we have a schematic of an overpass in front of us. Please point to the place where we see the value. If you point to the double headed arrow with the height of the overpass written in, you have pointed to a number signifying a distance from the highway to the bottom of the underpass. If you tell me that is Robert Moses' value, I will be most confused. There are lots of numbers in those blue prints. Are they all Moses' values or intentions? Some have to do with other features of roads, such as the depth of the roadbed. How do we differentiate the height of the overpass from the depth of the roadbed in a principled fashion as a human value and not arbitrarily? [...] if we look at the actual physical thing - the roads and bridges, etc. where are the values? I see bricks and stones and pavement, etc. But where are the values-do they have colors? How much do they weigh? How tall are they or how skinny? What are they? (2014: 95)

There are several problems with this argument, however. First, sometimes values are directly readable off design documents or material artifacts. Flanagan et al. (2008) discuss a computer-game environment for teaching girls to program, whose design documents explicitly state autonomy and gender equity as guiding values. Stating values in design documents is part of the methodology of value-sensitive design (Friedman and Kahn 2003). To be clear, my claim is not that design documents are the place that embodies the values of the artifacts they describe, but that design documents provide an empirical way to identify values that are embedded in the artifacts. Moreover, some artifacts bear slogans like "designed for fun" or "environmentally friendly," which explicitly express the values they are supposed to bear. Technology may also have expressive meaning that implicitly conveys values. The value of safety can be read off a "danger" sign. Sexist values in video games can be read off the representation of female 
characters with overly sexualized bodies, as trophies, or objects for sex and abuse by male characters (Sarkeesian 2013; 2016).

It might be objected that in these cases, values are embodied not in the artifacts, but only in their expressive content. A sign, so this objection goes, is a neutral instrument that may be used for delivering different messages; the value of safety is embodied only in the "danger" message, not the material artifact. Similarly, the sexist values are in the content of the video games rather than the computer hardware that runs them. ${ }^{5}$

This objection, however, wrongly assumes that content and the material means that stores, processes, or delivers it are sharply separable from each other. But content cannot be expressed without material means such as painted letters shaped in certain ways, or data physically stored in a magnetic medium or a solid-state drive. Second, in a "danger" road sign, for example, the value of safety is not merely in its message. Material features such as its shape and its reflection of the lights of passing cars are also ways in which it embodies the value of safety. Only a danger sign with certain physical properties embeds the value of safety. A flashing sign that distracts drivers from the danger from which it is supposed to warn them, or an unreadable sign does not embed safety. Similarly, current graphic cards have native hardware support for certain mathematical calculations needed to efficiently produce certain graphical effects. These effects are impossible to produce without such native hardware support (Adobe 2017). It has been claimed that Apple iPhone XS automatically recognizes when a selfie is taken, and processes the image in a value-laden way to look more attractive, e.g., by blurring age wrinkles and skin deformities (Pierini 2018). These photo enhancements are done by a custom image signal processor with an embedded neural engine on the phone's A12 processor (Fingas 2018). Since Apple is not transparent about its algorithms and hardware, it is hard to know what exactly goes on in this case. But supposing that some native hardware abilities have no useful 
uses other than enhancing selfies, then the graphic card may be said to embody social and aesthetic values.

I therefore suggest the following principle:

(Values-Principle) if a certain function is value-laden, and certain physical features of an artifact are required to effectively perform it, and the existence of these features in the artifact has no other reasonable justification, then the artifact may be said to embody the respective values. ${ }^{6}$

Another rationale that Pitt (2014: 94) gives for values' being empirically unidentifiable is that the same material object may mean different things to different people. If values are embedded in it, whose values are they? Pitt asks: if the Virginia Tech football stadium instantiates values, as some say, are they the university president's values, who sees it as a symbol of prestige, the football players' values, who see it as a step to a professional career in football, or the students', who see it as standing for all that is good about Virginia Tech?

An analogy with social facts helps counter Pitt's argument. As Searle (1995) argues, social facts are objective although their subsistence depends on subjects' beliefs. That this paper is a five-dollar bill depends on people's sharing a belief that it is. Yet it is still an objective fact in two senses. First, it is not just someone's subjective opinion that this is a five-dollar bill. Second, it is a five-dollar bill even if some people do not believe so. Analogously, a cross in a church or the US flag over the White House embed religious or national values, respectively, even if some individuals have idiosyncratic interpretations of their symbolic meaning. That the Virginia Tech stadium is less clear-cut does not show that artifacts cannot embody values. Moreover, a plausible subjective interpretation is constrained by physical features of the artifact. Had the university not valued football, a different design (especially scale) of a stadium would have been built. A dingy set of a dozen bleachers is not flexible to all possible interpretations. ${ }^{7}$ 
Another consideration that Pitt provides for VNT2 is that values allegedly embedded in artifacts may not promote the goals associated with them. For example,

if the university acquires its prestige by acting so as to develop a good football team at the expense of high academic standards or supporting faculty research, then it is not clear that the stadium embodies a good value (2014: 95).

Similarly, if because of the low overpasses, bus designers saw an opportunity to sell lower, more economical buses, then contra Moses' intentions, Afro-Americans could reach the beach by public transport (2014: 95).

We may distinguish two readings of this claim, epistemological, and ontological. According to its epistemological reading, these examples illustrate a difficulty with identifying embedded values by examining the consequences of design decisions. Since consequences may be unanticipated and unintended, consequences are bad evidence for inferring which values are embedded in the technology. But at most, these examples show a practical difficulty, rather than a principled impossibility. Identifying values is not always easy, but examining the consequences of technology is just one possible, fallible way to identify values.

A second reading of this argument is ontological (and goes beyond VNT2). It states that unintended consequences that promote goals inconsistent with the values allegedly embedded in a technology mean that they are not embedded in it after all. For example, if by lowering the bridges, Moses somehow helped Afro-Americans access the Long Island parks, the bridges did not embody racist values after all. I leave it open whether technology can embed values while de facto promoting goals that go against them. Even if it cannot, this claim does not vindicate VNT2, since in many cases, the consequences of a technology are correctly anticipated and resonate with the values embedded in it.

Examining unintended consequences of a technology can even reveal values embedded in it. For example, in a widely watched YouTube video, Zamen and Cryer (2009) accuse an HP 
camera of being "racist," because it tracks the movement of a white woman's face but not a black man's face. (Think what might happen if a similar glitch occurred in a camera installed in an autonomous car for identifying pedestrians.) Similarly, when color film was introduced, it included many pigments that would capture bright skin tones, but not skin tones of people of color, which would come out monotonous. The standard card that was used to calibrate the colors in photo development contained a photo of a white woman, thus photos of people of color would often not match their actual shades (Roth 2009). Such seemingly unintended consequences may reveal technology makers' tacit racist value judgments about their users' needs, which they embedded in the technologies.

During its design process, identifying values in technology is possible by deliberating on them (Friedman and Kahn 2003). Identifying values in existing technology is possible due to the following relation between values and reasons:

(VR) If $\mathrm{x}$ is valuable (in a certain respect) then one has reasons (of a certain kind) for a positive response (a pro-attitude or a pro-behavior) towards $\mathrm{x}$ (van de Poel and Kroes 2014: 108).

While the converse of VR is false (it is not necessarily true that if one has a reason for a positive response for $\mathrm{x}$, then $\mathrm{x}$ is valuable), VR nevertheless suggests we can identify values by examining whether our reasons are associated with any values. Indeed, Winner's (1980: 123) historical inquiry of Moses' bridges started when Winner wondered whether there was any reason the overpasses over the Long Island parkways were so low. Deliberating on the reason city bench seats are separated by dividers similarly reveals their sleep-prevention function, which reveals the anti-homeless values embedded in them (Rosenberg 2014).

It might be objected that the methods described above for identifying values are not empirical, because they involve wondering, deliberating, and reasoning, rather than direct 
observation. Thus, so this objection goes, they do not answer Pitt's worry about reading values off material artifacts. ${ }^{8}$ But as Longino (2002: 100) generalizes from multiple STS case studies:

Observation is not simple sense perception (whatever that might be) but an organized sensory encounter that registers what is perceived in relation to categories, concepts, and classes that are socially produced.

In science, establishing an empirical observation requires deliberation because the scientific community must be convinced that the alleged observation is intersubjectively verifiable. Moreover, observation is theory laden. To make sense, empirical observation must undergo a reasoning and deliberating process to be expressed in theoretical language. For example, without theoretical reasoning and interpretation, Thomson's (1897/2004: 364) claim of the discovery of the electron is little more than a description of a curious behavior of water drops near charged plates. Empirically identifying values in technology similarly involves theoretical reasoning, where the theories in question are normative.

\section{Is the negation of VNT trivial?}

So far, I argued that although there are empirically identifiable values in technology, values need not be empirically identifiable to be embedded. If I am right, VNT does not follow from Pitt's argument. Pitt's exact conclusion, however, is that either VNT true, or its negation is trivially true. Both VNT1 and VNT3 allow that technological artifacts embody values merely in a trivial sense. This section argues that the claim that technology embodies values is not trivial.

To argue that if technology embodies values, it does so only trivially, Pitt draws on Rudner (1953), who identifies two risks involved in scientific theory acceptance: accepting a false hypothesis ("false positive") and rejecting a true hypothesis ("false negative"). Rudner argues that rationally setting an evidential threshold for accepting hypotheses is impossible without considering these two risks. Values determine what risks are acceptable. Hence, scientists must consider values when accepting or rejecting hypotheses. For example, suppose 
that $\mathrm{X}$ is a method to cast a concrete ceiling. $\mathrm{X}$ is widely used and considered safe. Suppose that a significantly cheaper method $\mathrm{Y}$ can be used instead of $\mathrm{X}$. What is the level of certainty required to accept the hypothesis that $Y$ is safe? According to Rudner, there is no value-neutral answer. If scientists value safety more, they will raise the level of certainty. If they value reducing costs more, they will lower it. ${ }^{9}$

Pitt (2014: 98) argues that since humans make decisions based on epistemic judgments that are value laden in the way Rudner describes, the decisions are laden with the same values as the judgments on which they are based. Decisions about technology are no exception, and in this trivial sense, technology is value laden. When engineers adopt method $\mathrm{X}$ or $\mathrm{Y}$ from the previous paragraph they inevitably weigh costs versus safety. The ceiling they end up casting embodies the weighing they have made. But because there is nothing special about decisions about technology, so Pitt argues, the claim that technology is value-laden amounts to the trivial claim that human decisions are value laden.

Against this, I argue that what sets apart values embodied in technology, and renders them non-trivial, is their material longevity. When Moses designed the low overpasses to restrict Afro-Americans' beach access, racial segregation was prevalent in the US, and eugenics was legitimate science. While racism still exists, a tremendous movement away from racism has occurred in America. Yet Moses' bridges are still restricting Afro-Americans. As planner Lee Koppleman remarked, "The old son-of-a-gun had made sure that buses would never be able to use his goddamned parkways" (quoted in Winner 1980: 124; emphasis in origin). Because they are materially embedded in the bridges, Moses' values are impervious to the anti-racist social and political forces that have operated in the US, which makes their existence non-trivial.

It might be objected that just like racial practices can change, technology can be mended or replaced. The context of technology use may also change such that the technology stops 
bringing about the same effects as before, e.g., buses may become smaller and capable of passing under the bridges. Moreover, so this objection goes, social practices may also resist change. While changing entrenched social practices may be difficult, replacing or mending existing technology, especially on a large scale, has unique difficulties, which make the values embedded in the technology especially durable. Additionally, technology partly shapes its context of use, directing or constraining its replacement by new technology.

First, some amendments to technology are so complicated and expensive that they are practically or nearly impossible, or at least seem so. What would it take to make the New York Subway accessible to people with disabilities? The subway is like a rat-maze with many staircases, few elevators, train platforms that double as passageways with narrow shoulders due to support columns and staircases. Making it accessible would mean re-digging much of it while relocating massive water, electricity, and communications infrastructure. While originally designing it for accessibility was feasible, amending it now is practically impossible. ${ }^{10} \mathrm{~A}$ similar example is a failed attempt to replace a polluting highway that cuts through Maastricht with an environmentally friendly tunnel. "The main difficulties involved in the efforts to redesign the highway emanated from its embeddedness in the local traffic system, legal regulations, local user practices and the larger planning structure of Maastricht" (Hommels 2005, 124).11

Second, replacing existing technology often involves recovering lost knowledge embedded in it. This is a similar to exercises in computer-science textbooks that provide code of a "mystery" function and ask the student to find out what it does. Recovering such knowledge is difficult because technological systems outlive their original designers and users. New users and maintainers do not fully know how they work (Baird 2004: 13-14). ${ }^{12}$ Many organizations use critical, obsolete, legacy computer systems. As of 2016, for example, outdated 1970s computers that run assembly code on 8-inch floppy disks still control the U.S. nuclear arsenal, and there are 
more such obsolete systems still in use within the U.S. government (U.S. Government Accountability Office 2016). The programmers of such legacy systems, written in obsolete programming languages, and employees who knew pre-computer procedures are usually no longer around. As Conway (2019) puts this:

The more mature an application is, the less likely your organization is to have good knowledge of it. If you have a specification, has it been updated as the application has changed over the years? The staff that built it are less likely to still be with you, especially decades later. Your best source of knowledge may be how the application behaves today, and often that means the source code.

But as software engineer Joel Spolsky (2000) vividly writes, such source code is messy:

[Y]ou can ask almost any programmer today about the code they are working on. "It's a big hairy mess," they will tell you [...] Why is it a mess? "Well," they say, "look at this function. It is two pages long! None of this stuff belongs in there! I don't know what half of these API calls are for." [...] it's just a simple function to display a window, but it has grown little hairs and stuff on it and nobody knows why. Well, I'll tell you why: those are bug fixes. One of them fixes that bug that Nancy had when she tried to install the thing on a computer that didn't have Internet Explorer. Another one fixes that bug that occurs in low memory conditions. Another one fixes that bug that occurred when the file is on a floppy disk and the user yanks out the disk in the middle [...] Each of these bugs took weeks of real-world usage before they were found. The programmer might have spent a couple of days reproducing the bug in the lab and fixing it [...]. If it's like a lot of bugs, the fix might be one line of code, or it might even be a couple of characters, but a lot of work and time went into those two characters. When you throw away code and start from scratch, you are throwing away all that knowledge. All those collected bug fixes. Years of programming work.

Organizations are reluctant to replace critical legacy systems exactly because this may introduce unanticipated problems and require recovering lost knowledge embedded in them (Matthiesen and Bjørn 2015; Khadka et al. 2014). But as Pitt acknowledges, all this embedded knowledge is value laden, hence so are the systems, and non-trivially (cf. Nissenbaum 2001).

\section{Is denying VNT ill-motivated?}


Pitt's last line of argument does not directly defend VNT, but attacks the motivation to deny it. Pitt argues that denying VNT allows people to evade responsibility by blaming technology for their actions. But, so Pitt argues,

[m]achines don't make you do anything. That is the truth in the bumper-sticker "Guns don't kill, people kill." You choose to use this machine to commit that act. You can't blame the machine (2014: 96).

Pitt's argument, however, is problematic. First, the claim about evading responsibility cuts both ways. Weapon companies and dealers use VNT to evade responsibility for the consequences of their weapons by claiming they merely provide neutral tools. Second, technology does make you do things. Moses' low overpasses make public-transit users do something else than go to the beach. A wall around a luxury housing-complex in a poor neighborhood makes local residents go around it, and it makes is residents minimize their contact with the locals. Search engines involuntary induce changes in their users' belief formation processes (Miller and Record 2017). A workplace-toilet seat with an uncomfortable sitting positing makes employees spend less time in the toilets and more time working (Morrison 2019).

Second, as Dotson (2012: 329-333) argues, technology can nudge us; namely, exploit psychological facts about how humans make decisions to influence their decisions (Thaler and Sunstein 2009). For example, smartphones provide users with an endless stream of information, which mitigate their boredom while sparing them the anxiety of interacting with strangers. Smartphones provide many customization options, which make their users feel the satisfaction of having choices - all of them meaningless. Smartphones do not force their owners to use them; they lure them. The values embedded in smartphones are of "technological liberalism"-a depressing conception of the good life, in which socially isolated individuals realize themselves by consuming goods and excelling in meaningless tasks, or so Dotson argues. 
Moreover, technology opens up possibilities for practicable action, which partly define our responsibilities and normative expectations. A responsible subject is not expected to do more than what is practicable, but when an activity becomes practicable, performing it might become a minimal requirement for acting responsibly. For example, in the beginning of the modern Olympic Games, judges visually determined sprint-race winners, but photo-finish cameras became required for this determination soon after the technology became available (Miller and Record 2013: 125; Record 2013: 329). Technological possibilities partly define our future plans too. One cannot go to the Caribbean on vacation or become a commercial pilot without the possibilities afforded by jet planes. Since we define the good life in terms of our future plans, technological possibilities and the respective values embodied in them partly shape our conceptions of the good life, which in turn influence our actions (Kiran and Verbeek 2010: 418-419).

\section{What is at stake in this debate?}

So far I argued that technology is value laden, rather than merely a neutral instrument. But the debate about VNT may seem as an empty play of words. Does it matter whether the technology itself is value laden or only its uses are? Aren't these two equivalent ways to say the same thing? This section argues that they are not, and that this philosophical debate has genuine practical moral significance.

I will draw on Katz's (2005) analysis of Nazi death camps as a technology embedded with evil values:

The physical objects that constituted the structure of the camps, as well as the organizational system that operated the camps, were human creations, designed with a set of specific purposes in mind. These purposes were evil, as is well known; but more importantly, the evil of the death camps was designed into the technological artifacts themselves. The death camps were not, as the commonplace idea might suggest, morally neutral artifacts that were simply used in an evil way. The death camps were not value 
free, and as human-created technological systems they thus stand as a powerful counterexample to the idea that technological artifacts are morally neutral.

Katz (2005: 415-416) supports his argument by analyzing the physical features of the artifacts used in the death camps. The furnaces for disposing of bodies of the mass-murdered, most of them Jews, had unique features that distinguished them from ordinary corpse furnaces. They had more muffles and chambers to speed up the process, lacked aesthetic ornaments, and did not separate the ashes of different bodies (as there was no ceremonial burial by grieving people). Similarly, the gas chambers were designed to maximize both efficiency in killing and secrecy. ${ }^{13}$

Katz's analysis reveals three ways the philosophical debate on VNT has moral consequences on the ground. Designers, engineers, technicians, and bureaucrats use VNT to evade responsibility for the harmful consequences of their technologies. In the Nuremberg trials, architect Albert Speer (1905-1981), who was Reich Minister of Armaments and War Production for Nazi Germany, denied responsibility for the systematic extermination of Jews in the Holocaust. He presented himself as dealing merely with the technical aspects of buildings and facilities, and claimed he did not concern himself with politics. As Katz (2005: 413) comments:

Here then is an explanation based on the political and moral neutrality of the technological enterprise of architecture. As the mere architect, involved with the design and creation of buildings, Speer cannot be concerned with the political and moral meaning of the things he produces for the master he serves.

Second, VNT may prevent engineers and technicians from asking moral questions about their labor. When engineers and technicians see technology as value neutral, they leave it to its users to ponder about its moral and political implications. Because they generally prefer to think that technology is value neutral, engineers and technology developers may resist a discussion of values, see it as impeding their technical work, and not as part of their responsibilities (Shilton 2018). Speer candidly admits he exploited this state of mind for the benefit of the Third Reich: 
Basically, I exploited the phenomenon of the technician's often blind devotion to his task. Because of what seems to be the moral neutrality of technology, these people were without any scruples about their activities. The more technical the world imposed on us by the war, the more dangerous was this indifference of the technician to the direct consequences of his anonymous activities (Speer 1970: 212, quoted in Katz 2005: 420).

Third, if VNT is false, there are inherent restrictions on legitimate use of technologies, which do not exist if VNT is true. Suppose that most of the population has turned into flesh-eating zombies that endanger those who have not turned zombies. Suppose non-zombie humans are considering building zombie death camps equipped with gas chambers and furnaces. Or consider the scenario from the science fiction series Torchwood: Miracle Day (2011), in which all human beings cease dying. Government officials, who had secretly planned for this contingency, had built furnaces for permanently burning those deemed not worthy of living anymore, such as the extremely ill or extremely old. If VNT is true, it is permissible to build such death furnaces in preparation for such a contingency, since these furnaces are morally neutral. Only their use can be deemed good or bad. If VNT is true, in extreme circumstances, such extreme technological solutions may be acceptable. But if VNT is false, and Katz's argument is right, then gas chambers for mass killing of zombies or furnaces for mass disposing of living people or corpses are inherently evil. Hence, they should not be built even in extremely pressing conditions (in the Holocaust, Jews were descried by Nazis as sub-humans, just like the zombies or the barely living in the fictional examples). Conversely: if a technology is laden with good values, it should be generally preferred over other solutions.

VNT proponents might object that engineers should refrain from constructing death camps not because death camps embed evil values, but because engineers should reasonably expect value-neutral death camps to be used for evil ends. Expectations of possible negative uses of a neutral technology, however, provide a weaker reason to refrain from constructing it than its embodying negative values. If VNT is correct, there must be both negative and positive uses 
for death camps. Otherwise, how are they neutral? If VNT is correct, then, when deciding whether to construct death camps, engineers must weigh the possible negative and positive uses against each other. Such alleged positive reasons make the case from possible uses against constructing death camps weaker than the case from the evil values embedded in death camps.

Moreover, we can always conceive of some positive uses or outcomes for even the most evil practices. On the one hand, slavery robs humans of their dignity, autonomy and bodily integrity; on the other hand, it creates economic growth and reduces prices. But when we morally evaluate slavery, we do not weigh its harms against its benefits, but deem it evil regardless of its alleged benefits. The same goes for death camps.

\section{Conclusion}

Pitt's defense of the value-neutrality of technology is unsuccessful. Due to their physical properties, technological artifacts are part of the normative order, rather than external to it. Technology designers and constructors cannot evade moral responsibility for the consequences of their products by arguing that they are morally neutral, and only their users may be culpable for using them in certain ways.

Outside STS and philosophy of technology, technology is often assumed to be valueneutral, thus the development of technology, as opposed to its uses, escapes ethical debate. ${ }^{14}$ Unlike STS scholars, philosophers with traditional training in ethics typically lack the concepts and sensibilities to deal with the moral dimensions of technology (Jonas 1973). But surprisingly, within STS, explicit normative assessment of technology is rare. Most published books and research papers in STS restrict themselves to descriptive and methodological claims, and refrain from making prescriptions, condemnation, or praise of technology; "academics-particularly in the field of science studies-have not done [work] in making plain the harms that inhere in and are produced by particular kinds of technologies" (Moore 2019: 20). ${ }^{15}$ This paper stressed ways 
to empirically identify values embedded in technological artifacts. I hope that this will be taken up in STS not only to analyze the values that are in technology, but also the values that we ought and ought not to embed in it. As Martin (2019: 12) argues, such a discussion can serve as a springboard for developing interventions in the world to resist evil technologies, and educate people to avoid evil and promote good through technology.

\section{$\underline{\text { References }}$}

Adobe. 2017. Photoshop Graphics Processor (GPU) Card FAQ. (December 21). helpx.adobe.com/photoshop/kb/photoshop-cc-gpu-card-faq.html

Agassi, J. 1985. Technology: Philosophical and Social Aspects. Dordrecht: Reidel.

Akrich, M. 1992. The De-scription of technical objects. In Shaping Technology/Building Society: Studies in Sociotechnical Change, eds. W. Bijker and J. Law, 205-224. Cambridge, MA: MIT Press.

Andler, D. 2012. What has collective wisdom to do with wisdom? In Collective Wisdom: Principles and Mechanisms, eds. H. Landemore and J. Elster, 72-84. Cambridge: Cambridge University Press.

Audi. R. 2003. Epistemology: A Contemporary Introduction to the Theory of Knowledge, $2^{\text {nd }}$ ed. New York: Routledge.

Baird, D. 2004. Thing Knowledge: A Philosophy of Scientific Instruments. Berkeley: University of California Press.

Bijker, W. E. 1995. Of bicycles, bakelites, and bulbs: toward a theory of sociotechnical change. Cambridge, MA: MIT Press.

Bunge, M. 1977. The philosophical richness of technology. In PSA 1976: Proceedings of the Biennial Meeting of the Philosophy of Science Association, Volume Two, ed. F. Suppe and P. D. Asquith, 153-172. East Lansing, MI: PSA.

Canada, G. 1995. Fist, Stick, Knife, Gun: A Personal History of Violence in America. Boston: Beacon Press.

Carlson, D. 2015. 1980s computer controls GRPS heat and AC. WOODTV.com (12 June). woodtv.com/2015/06/11/1980s-computer-controls-grps-heat-and-ac/

Conway, M. 2019. Why your COBOL code isn't going anywhere. TechBeacon (16 September). techbeacon.com/app-dev-testing/why-your-cobol-code-isnt-going-anywhere 
Dickinson, T. 2018. All-American killer: how the AR-15 became mass shooters' weapon of choice. Rolling Stone (February 22). www.rollingstone.com/politics/features/how-thear-15-became-mass-shooters-weapon-of-choice-w451452

Dotson, T. 2012. Technology, choice and the good life: questioning technological liberalism. Technology in Society 34: 326-336.

Dotson, T. 2015. Technological determinism and permissionless innovation as technocratic governing mentalities: psychocultural barriers to the democratization of technology. Engaging Science, Technology, and Society 1: 98-120.

Dotson, T. 2017. Technically together: Reconstructing community in a networked world. Cambridge, MA: MIT Press.

Douglas, H. 2009. Science, Policy, and the Value-Free Ideal. Pittsburgh: University of Pittsburgh Press.

Epting, S. 2016. The moral dimensions of infrastructure. Science and Engineering Ethics 22(2): 435-449.

Fingas, R. 2018. Apple said to be working on fixing 'aggressive' skin smoothing in iPhone XS photos. Appleinsider (September 28). appleinsider.com/articles/18/09/28/apple-said-tobe-working-on-fixing-aggressive-skin-smoothing-in-iphone-xs-photos

Flanagan, M., D. C. Howe and H. Nissenbaum. 2008. Embodying values in technology: theory and practice. In Information Technology and Moral Philosophy, ed. J. van den Hoven and J. Weckert, 322-353. Cambridge: Cambridge University Press.

Friedman, B. and P. H. Kahn, Jr. 2003. Human values, ethics, and design. In The HumanComputer Interaction Handbook, ed. J. A. Jacko and A. Sears, 1177-1201. Mahwah, NJ: Lawrence Erlbaum Associates.

Hommels, A. 2005. Unbuilding Cities: Obduracy in Urban Sociotechnical Change. Cambridge, MA: MIT Press.

Humphreys, P. 2009. Network epistemology. Episteme 6(2): 221-229.

Ihde, D. 2009. Postphenomenology and Technoscience: The Peking University Lectures. Albany, NY: SUNY Press.

James, W. 1907. Pragmatism: A New Name for Some Old Ways of Thinking. New York: Longmans, Green, and Co.

Joerges, B. 1999. Do politics have artifacts? Social Studies of Science 29(3): 411-431.

Johnson, D. G., and J. M. Wetmore. 2008. STS and ethics: implications for engineering ethics. In The Handbook of Science and Technology Studies, $3^{\text {rd }}$ ed., eds. E. J. Hackett, 0.

Amsterdamska, M. Lynch and J. Wajcman, 567-582. Cambridge, MA: MIT Press. 
Jonas, H. 1973. Technology and responsibility: reflections on the new tasks of ethics. Social Research 40(1): 31-54.

Katz, E. 2005. On the neutrality of technology: the Holocaust death camps as a counterexample. Journal of Genocide Research 7(3): 409-421.

Khadka R., B. V. Batlajery, A. M. Saeidi, S. Jansen, and J. Hage. 2014. How do professionals perceive legacy systems and software modernization? In Proceedings of the 36th International Conference on Software Engineering (ICSE 2014), 36-47. New York: ACM.

Kiran, A. H. and P. P. Verbeek. 2010. Trusting our selves to technology. Knowledge, Technology \& Policy 23(3-4): 409-427.

Kirkman, R. 2009. At home in the seamless web: agency, obduracy, and the ethics of metropolitan growth. Science, Technology and Human Values 34(2): 234-258.

Lachney, M. and T. Dotson. 2018. Epistemological luddism: reinvigorating a concept for action in $21^{\text {st }}$ century sociotechnical struggle. Social Epistemology 32(4): 228-240.

Latour, B. 1994. On technical mediation. Common Knowledge 3(2): 29-64.

Latour, B. 2002. Morality and technology: the end of the means. Theory, Culture \& Society 19(5-6): 247-260.

Lehrer, K. 1995. Knowledge and the trustworthiness of instruments. The Monist 78(2): 156170.

Longino, H. 2002. The Fate of Knowledge. Princeton: Princeton University Press.

Martin, B. 2019. Technology and evil. Social Epistemology Review and Reply Collective 8(2): $1-14$.

Matthiesen, A. and P. Bjørn. 2015. Why replacing legacy systems is so hard in global software development: an information infrastructure perspective. In Proceedings of the 18th ACM Conference on Computer Supported Cooperative Work \& Social Computing (CSCW '15), 876-890. New York: ACM.

Miller, B. 2014A. Catching the WAVE: the weight-adjusting account of values and evidence. Studies in History and Philosophy of Science 47: 69-80.

Miller, B. 2014B. Science, values, and pragmatic encroachment on knowledge. European Journal for the Philosophy of Science 4(2): 253-270.

Miller, B. and I. Record. 2013. Justified belief in a digital age: on the epistemic implications of secret internet technologies. Episteme 10(2): 117-134.

Miller, B. and I. Record. 2017. Responsible epistemic technologies: a social-epistemological analysis of autocompleted Web search. New Media and Society 19(12): 1945-196. 
Moore, K. 2019. Refusing evil by (sociotechnical) design: a comment on Martin (Revised). Social Epistemology Review and Reply Collective 8(4): 19-23.

Morrison, R. 2019. Say goodbye to comfort breaks! New downward-tilting toilets are designed to become unbearable to sit on after five minutes. The Daily Mail (December 18). www.dailymail.co.uk/sciencetech/article-7801245/Toilets-tilted-downwards-13degrees-stop-workers-spending-long-loo.html

Nissenbaum, H. 2001. How computer systems embody values. Computer 34(3): 118120.

Pierini, D. 2018. Beautygate: Apple might 'fix' iPhone XS selfie camera. Cult of Mac (September 18). www.cultofmac.com/579942/beautygate-iphone-xs-selfies/

Pitt, J. C. 2000. Thinking about Technology. New York: Seven Bridges Press.

Pitt, J. C. 2007. Speak to me. Metascience 16: 51-59.

Pitt, J. C. 2014. "Guns don't kill, people kill”; values in and/or around technologies. In The Moral Status of Technical Artifacts, eds. P. Kroes and P. P. Verbeek, 89-101. Dordrecht: Springer.

Popper, K. R. 1972. Objective Knowledge: An Evolutionary Approach. Oxford: Clarendon Press.

Radder, H. 2009. Why technologies are inherently normative. In Philosophy of Technology and Engineering Sciences, ed. A. Meijers, pp. 887-921. Amsterdam: Elsevier.

Record, I. 2013. Technology and epistemic possibility. Journal for General Philosophy of Science 44(2): 319-336.

Rosenberger R. 2014. Multistability and the agency of mundane artifacts: from speed bumps to subway benches. Human Studies 37: 369-392.

Roth, L. 2009. Looking at Shirley, the ultimate norm: colour balance, image technologies, and cognitive equity. Canadian Journal of Communication 34(1): 111-136.

Rudner, R. 1953. The scientist qua scientist makes value judgments. Philosophy of Science 20(1): 1-6.

Sarkeesian A. 2013. Tropes vs Women in Video Games - Season 1. www.youtube.com/ playlist?list=PLn4ob 5 ttEaA vc8F3fjzE62esf9yP61

Sarkeesian A. 2016. Tropes vs Women in Video Games - Season 2. www.youtube.com/ playlist?list=PLn4ob 5 ttEaZWIYcx7VKiFheMSEp1gbq

Searle, J. 1995. The Construction of Social Reality. New York: Free Press.

Selinger, E. 2012. The philosophy of the technology of the gun. The Atlantic (July 23). www.theatlantic.com/technology/archive/2012/07/the-philosophy-of-the-technologyof-the-gun $/ 260220 /$ 
Shew, A. 2017. Animal Constructions and Technological Knowledge. Lanham, MD: Lexington Books.

Shilton, K. 2018. Engaging values despite neutrality: challenges and approaches to values reflection during the design of internet infrastructure. Science, Technology, \& Human Values 43(2): 247-269.

Speer, A. 1970. Inside the Third Reich: Memoirs, translated by Richard and Clara Winston. New York: Simon and Schuster.

Spolsky, J. 2000. Things you should never do, part I. Joel on Software (April 6). www.joelonsoftware.com/2000/04/06/things-you-should-never-do-part-i

Star S. L. and Ruhleder K. 1996. Steps toward an ecology of infrastructure: design and access for large information spaces. Information Systems Research 7(1): 111-134.

Thaler R. H. and Sunstein C. R. 2009. Nudge: Improving Decisions about Health, Wealth, and Happiness. New York: Penguin.

Thomson, J. J. 1897/2004. The Death of the Atom. In Scientific Revolutions: Primary Texts in the History of Science, ed. B. S. Baigrie, 359-366. Upper Saddle River, NJ: Pearson.

U.S. Government Accountability Office. 2016. Information Technology: Federal Agencies Need to Address Aging Legacy Systems, by D. A. Powner. GA0-16-468, Washington, DC. www.gao.gov/assets/680/677454.pdf

van de Poel, I. and P. Kroes. 2014. Can technology embody values? In The Moral Status of Technical Artifacts, eds. P. Kroes and P. P. Verbeek, pp. 103-124. Dordrecht: Springer.

Verbeek, P. P. 2008. Morality in design: design ethics and the morality of technological artifacts. In Philosophy and Design: From Engineering to Architecture, eds. P. Kroes, P. E. Vermaas, A. Light and S. A. Moore, pp. 93-103. Dordrecht: Springer.

Verbeek, P. P. 2011. Moralizing Technology: Understanding and Designing the Morality of Things. Chicago: University of Chicago Press.

Winner, L. 1980. Do artifacts have politics? Daedalus 109(1): 121-136.

Woolgar, S. and G. Cooper. 1999. Do artifacts have ambivalence? Moses' bridges, Winner's bridges, and other urban legends. Social Studies of Science 29(3): 433-449.

Zamen, W. and D. Cryer. 2009. HP Computers Are Racist. youtu.be/t4DT3tQqgRM 
1 They include Akrich (1992), Bunge (1976), Flanagan et al. (2008), Friedman and Kahn (2002), Latour (2002), Martin (2019), Nissenbaum (2001), Radder (2009), van de Poel and Kroes (2014), and Winner (1980).

${ }^{2}$ Here are intuitive examples for each category:

\begin{tabular}{|l|l|l|}
\cline { 2 - 3 } \multicolumn{1}{c|}{} & Intrinsic & Extrinsic \\
\hline Final & Wisdom & Holiness \\
\hline Instrumental & Education & Fashionableness \\
\hline
\end{tabular}

Wisdom is intrinsic-final: intrinsic because wisdom resides in the person who manifests it and is not relative to an external evaluation framework, which is what distinguishes it from mere intelligence (Andler 2012); wisdom is final because attaining wisdom is not a means of attaining something else. Education is arguably instrumental-final: final because being educated is a property of the person herself; instrumental because education is not sought for its own sake, but as a means of attaining another value, such as wisdom. Holiness is extrinsic-final; extrinsic because it is relative to a religious evaluation system (a holy artifact in one religion may not be holy in another); holiness it is final because holiness resides in the thing that manifests it. Fashionableness is extrinsic-instrumental; extrinsic because it is relative to a changing fashion; instrumental because it is not sought for its own sake, but for other values, such as attractiveness.

${ }^{3}$ Unlike van de Poel and Kroes (2014), I use the terms "values" to describe both positive and negative values ("disvalues," in their terminology). Thus, by saying that Moses' bridges embody racist values, I am not approving of these values.

${ }^{4}$ For an extended argument from mediation theory against the value-neutrality of guns, see Selinger (2012). See also Latour (1994).

5 I thank Shaul Katzir for this objection.

${ }^{6}$ This is a sufficient condition, not a necessary one. The HP camera and the colour film examples discussed later in this section do not fall under it.

${ }^{7}$ I thank an anonymous reviewer for this point.

${ }^{8}$ I thank an anonymous reviewer for this objection.

${ }^{9}$ For a defence and generalization of Rudner's argument see Douglas (2009), and Miller (2014B).

${ }^{10}$ Or consider a more modest example: a single obsolete 30-year-old Commodore Amiga computer still controls (as of 2015) the air conditioning at nineteen public schools in Grand Rapids, Michigan. A local high school student who programmed it in the 1980 s is still occasionally called back to maintain it. Replacing it with a current system would cost between $\$ 1.5$ and 2 million (Carlson 2015). 
11 Social constructivists of technology, e.g., Bijker (1995), argue that technology has interpretative flexibility: it can accommodate several competing interpretations of its functions and features. Accordingly, for social constructivists, technology remains in place as long as there is a stable consensus about its interpretation and need. This view can indirectly challenge the claim that values are embedded in technological artifacts, since it may be argued that the values are in the interpretation, rather than the artifact. Social constructivist explanation of technological endurance, however, is at the very least partial and oversimplified. While a social consensus may be partly responsible for the longevity of a technology, it is typically not the sole factor. First, as I argued regarding the Virginia Tech football stadium, interpretive flexibility has limits: an artifact's material features constrain its plausible interpretations. Second, the notion of interpretive flexibility is usually employed for describing early stages in the development of a technology; in later stages "a stabilization of a technological frame [of interpretation] can cross a threshold beyond which, for all practical purposes, it becomes permanently obdurate" (Kirkman 2009, 242). Third, as Hommels writes with respect to the Maastricht highway:

Because technological frames are usually tied to specific social groups, this interactionist theoretical perspective [namely, social constructivism of technology] only provided a partial explanation of what constitutes obduracy. Major urban structures, however, tend to be embedded in a larger built-up urban environment and this generally causes major challenges when for some reason that structure needs to be redesigned. Obduracy here is explained by its relationship to other actants, rather than by the interests and interpretations of relevant social groups $(2005,123)$.

I thank an anonymous reviewer for these references.

12 Some philosophers recognize a sense of "knowledge" that refers to knowledge that exists in books and documents, as opposed to a subject's mind. As Humphreys (2009: 221) writes:

In traditional epistemology, sources of knowledge need not possess knowledge themselves [...] but we do speak of computers storing and processing knowledge as well as information, language that is not just metaphorical. Printed books contain knowledge and so do their on-line versions.

Such type of knowledge goes by names, such as "objective knowledge" (Popper 1972) "virtual knowledge" (Audi 2003: 265-267) or "thing knowledge" (Baird 2004). According to Humphreys' analysis (2009: 222), "[a] computational device has knowledge of a system just in case the device possesses a true, evidentially supported model of the system." Baird (2004) characterizes this knowledge as ideas (of the kind that populate Popper's (1972) "Third World") that are physically embedded in material artifacts, and Shew (2017) expands the account to include animal tools. Pitt (2007) objects to Baird's account because it is incompatible with Peirce's pragmatist account of knowledge. I am not committed to all aspects of Baird's or Humphreys' theories, specifically to Baird's revised version of Popper's three-world metaphysics or to Baird's claim that instruments work because they materially embed their makers' knowledge. By claiming that replacing existing technology involves recovering lost knowledge embedded in it, I am referring to information that is codified in them and does not necessarily exist in anybody's mind anymore.

${ }^{13}$ I agree with Epting (2016) that infrastructures embed moral values. As a technological infrastructure, a Nazi death camp embeds evil values. However, infrastructures contain people, procedures, standards, and labour to mention just a few - in addition to material artifacts (Star and Ruhleder 1996). A VNT proponent may insist that within a technological infrastructure, only things other than material artifacts embed values. The stronger claim this paper and Katz (2005) defend is that material artifacts themselves - the bricks and iron parts - can embed values.

${ }^{14}$ Cf. Dotson (2015), which makes a similar claim about the effects of the widespread view of technological determinism. 
15 For a plea for STS scholars to engage in ethics of technology, which has been mostly ignored, see Johnson and Wetmore (2008). Dotson's (2017) book, which explicitly takes a normative moral stance, is an exception that proves the rule. 